\title{
THE VANISHING PHYSICIAN-SCIENTIST?
}

\author{
Andrew I. Schafer, M.D. \\ The E. Hugh Luckey Distinguished Professor of Medicine, Chairman, Department of Medicine, Weill \\ Cornell Medical College, and Physician-in-Chief, New York-Presbyterian Hospital/Weill Cornell \\ Medical Center, New York, NY 10065, Tel: 212-746-4720, ais2007@med.cornell.edu
}

Three decades have transpired since James Wyngaarden, later to become Director of the National Institutes of Health (NIH), rang the first alarm about physician-scientists as an "endangered species" (1). Indeed, trends since then appear to be increasingly discouraging. While NIH grant applications and awards to investigators with Ph.D. degrees have steadily risen, and in fact surged during the 5-year period of doubling of the NIH budget from 19972002, they have remained flat even during boom years for those with M.D. only degrees. The physician-scientist workforce has also been aging. The mean age at which a first independent NIH grant is awarded is now approaching 43 (having been only 39 less than a decade ago), clearly an untenable situation and an unsustainable trend. And while most attention has been directed at efforts to expand the pipeline of clinical investigators, I believe an even more critical problem has been their attrition from what is indeed an extremely leaky pipeline. Up to onethird of young investigators with K-type (mentored) NIH grants don't even apply for independent R01 grants and many more are lost at later stages.

"Physician-scientists" can be broadly defined as those with M.D. degrees (alone or combined with other advanced degrees) who devote a substantive percent of their professional effort to research anywhere along the entire spectrum of biomedical inquiry, ranging from basic science, through translational and patient-oriented research, to the evaluative sciences. However, it is time to reassess our fixed image of the idealized physician-scientist as the much lamented "triple threat" academic. Indeed, was there ever really a time when large numbers of physicians actually moved effortlessly between the bench, the clinic and the classroom on a typical day? More realistically, I think the prototypical "triple threats" went through transitions in their careers where during certain periods they were immersed in primarily clinical practice (especially during training and early years) to primarily "protected time" for research (typically in mid-career) to more administrative responsibilities (in later years). As we plan for physician involvement in medical research in future generations, we must be careful to not confine our definition of a serious physician-scientist to this largely mythical "triple threat" model.

As described in the recently published book, The Vanishing Physician-Scientist? (2), physicians over the centuries have been able to continually adapt to the times in which they worked, even during environmental hardships that were at least as challenging as the ones we have faced, repeatedly reinventing their roles in the research enterprise to allow them to make major contributions. However, the times must be understood. As the book explores from social, cultural, economic and political perspectives, today there are enormously challenging

(C) 2009 Mosby, Inc. All rights reserved.

Publisher's Disclaimer: This is a PDF file of an unedited manuscript that has been accepted for publication. As a service to our customers we are providing this early version of the manuscript. The manuscript will undergo copyediting, typesetting, and review of the resulting proof before it is published in its final citable form. Please note that during the production process errors may be discovered which could affect the content, and all legal disclaimers that apply to the journal pertain. 
contemporary forces that must be recognized and addressed to preserve - indeed to revitalize - the physician-scientist workforce of tomorrow.

First, there must be a clear appreciation of the rapidly growing chasm that has developed between practicing clinicians and biomedical scientists. The breathtaking pace of progress in not only areas of medical science like molecular biology but also in the clinical prevention, diagnosis and treatment of disease has created a virtual language barrier between researchers (including physician-scientists) and medical practitioners. Since the vast and dramatically changing bodies of knowledge in both of these arenas of medicine have made it humanly impossible for any one individual to attain even a semblance of mastery of much of it, effective communication and team building will become increasingly more vital. The assembly of such teams to compete for multicenter or program project grants is merely the starting point of what will have to be well led, dynamic, nimbly adaptable, constantly scrutinized and ruthlessly evaluated intellectual critical masses that are institutionally or philanthropically buffered from the destructive vagaries of research funding.

Second, it must be accepted - and in fact embraced - by the current generation of established physician-scientists that their progeny will look very different and have different priorities and needs. Women have rapidly attained parity in numbers as medical school graduates, yet they continue to generally regard research careers as inhospitable to their career advancement. Without reversing this, we are facing the unacceptable prospect of losing the enormous intellectual firepower of women physicians engaged in research. Both female and male medical school graduates today have strikingly different attitudes than previous generations in attitudes about work-life balance and the importance of controllable lifestyles. (Interestingly, while most of them consider these choices to be incompatible with research careers, quite the opposite might be the case.) Medical schools and academic medical centers have been extraordinarily slow in responding to these demographic and social changes. They cling to historical academic systems of tenure clocks and "up or out" promotion policies that were created for previous generations of physician-scientists who were almost entirely male, with stay-at-home wives. However, the corporate ladder model of this rigidly linear career track will result in even more alarming attrition from the physician-scientist workforce. Those institutions that can accommodate young physicians with highly flexile promotion systems that more resemble corporate "lattices" than "ladders" will quickly find themselves at a huge competitive advantage in recruiting and retaining the most gifted physician-scientists.

Finally, the role of effective mentoring will become more important than ever in promoting successful physician-scientist careers in the future. But, just like the "lone ranger" model of individual investigators is giving way to biomedical research as a team sport, contemporary models of mentoring for each individual developing physician-scientist will often require cohesive teams of transgenerational, dedicated mentors who can provide committed (and compensated) time to this irreplaceable function.

Physicians have always played an irreplaceable role in medical discovery, bringing to their research work the unique perspective of their own experiences with caring for patients. Their disappearance from the front lines of medical inquiry would cripple the biomedical research enterprise. This is not to suggest that Ph.D. scientists are any less important. In fact, the future vigor of medical research will depend on even closer partnerships between physician and Ph.D. investigators. In his book, The Crisis in Clinical Research, Edward Ahrens wondered "whether young MDs and PhDs are not ideally equipped to train each other" (3). Just as physicianscientists have benefitted immensely from extensive, hands-on training in basic laboratory science throughout much of the $20^{\text {th }}$ century, in recent years an increasing number of Ph.D. graduate programs in biomedical fields have begun to provide their students with structured exposure to clinical medicine. 
The future viability and vitality of the physician-scientist workforce pose unique challenges. The continued alienation of women physicians from pursuing durable research careers, the failure of medical schools to accommodate for variability in individual lifestyle choices at different career stages, and the ossification and decay in mentoring for young physicianscientists, combined with the increasing unpredictability of support for research caused by more extreme boom-or-bust, feast-or-famine fluctuations in grant funding, will likely drive more and more potential physician-scientists into other, more secure career paths that are uniquely available to them. It will take an unprecedented confederation of well-coordinated stakeholder organizations to relentlessly advocate for the necessary changes by federal and private research funding agencies and by medical schools to secure a bright future for a robust physician-scientist workforce.

\section{REFERENCES}

1. Wyngaarden JB. The clinical investigator as an endangered species. N Engl J Med 1979;301:12541259. [PubMed: 503128]

2. Schafer, AI., editor. The Vanishing Physician-Scientist?. Ithaca: Cornell University Press; 2009.

3. Ahrens, EH, Jr. The Crisis in Clinical Research. Overcoming Institutional Obstacles. New York: Oxford University Press; 1992. 